\title{
Perception of temperature and wind by users of public outdoor spaces: relationships with weather parameters and personal characteristics
}

\author{
Henrique Andrade • Maria-João Alcoforado • \\ Sandra Oliveira
}

Received: 25 February 2010/Revised: 6 September 2010 /Accepted: 2 October 2010 /Published online: 30 October 2010

(C) ISB 2010

\begin{abstract}
We aim to understand the relationship between people's declared bioclimatic comfort, their personal characteristics (age, origin, clothing, activity and motivation, etc.) and the atmospheric conditions. To attain this goal, questionnaire surveys were made concurrently with weather measurements (air temperature, relative humidity, solar and long-wave radiation and wind speed) in two open leisure areas of Lisbon (Portugal), during the years 2006 and 2007. We analysed the desire expressed by the interviewees to decrease, maintain or increase the values of air temperature and wind speed, in order to improve their level of comfort. Multiple logistic regression was used to analyse the quantitative relation between preference votes and environmental and personal parameters. The preference for a different temperature depends on the season and is strongly associated with wind speed. Furthermore, a general decrease of discomfort with increasing age was also found. Most people declared a preference for lower wind speed in all seasons; the perception of wind shows significant differences depending on gender, with women declaring a lower level of comfort with higher wind speed. It was also found that the tolerance of warmer conditions is higher than of cooler conditions, and that adaptive strategies are undertaken by people to improve their level of comfort outdoors.
\end{abstract}

Keywords Bioclimatic comfort · Personal parameters . Thermal environment . Outdoor spaces · Weather perception

H. Andrade $(\bowtie) \cdot$ M.-J. Alcoforado $\cdot$ S. Oliveira

Centre of Geographical Studies, University of Lisbon,

Lisbon, Portugal

e-mail: henr.andr@gmail.com

\section{Introduction}

The assessment of bioclimatic comfort in outdoor areas is a complex task, due to the high variability of the outdoor environment conditions and the influence of subjective factors (especially psychological and cultural) in the perception of the atmospheric environment (Höppe 2002; Spagnolo and De Dear 2003; Knes and Thorsson 2006; Nikolopoulou and Lykoudis 2006; Oliveira and Andrade 2007; Lin 2009). It is currently well known that models developed to assess indoor conditions, based on the human body thermal balance (Fanger 1972; Gagge et al. 1986; Parsons 1993), are inadequate to understand outdoor thermal comfort, since they can only be used as an approach to assess the thermophysiological component of the thermal comfort.

Recent studies on this subject combine measurements of weather parameters with interviews, with the aim of understanding the complex relationships between meteorological and personal (including psychological) factors in the perception of the atmospheric environment (Ahmed 2003; Givoni et al 2003; Spagnolo and De Dear 2003; Stathopoulos et al. 2004; Knes and Thorsson 2006; Lin and Matzarakis 2008).

A study on the perception of atmospheric conditions by users of urban open spaces was carried out in Lisbon during the years of 2006 and 2007; its main purpose was to improve knowledge on the relationships between outdoor microclimatic conditions and the perception of bioclimatic comfort, which can contribute to improving the design of urban outdoor spaces. The first results (concerning data from late winter and spring of 2006) are explained in Oliveira and Andrade (2007); in this initial experience, the questionnaires were used in just one open space in Lisbon (Belem) located in the southern part of the city (Fig. 1).

All the results obtained during this 2-year study about the perception of air temperature and wind speed are 


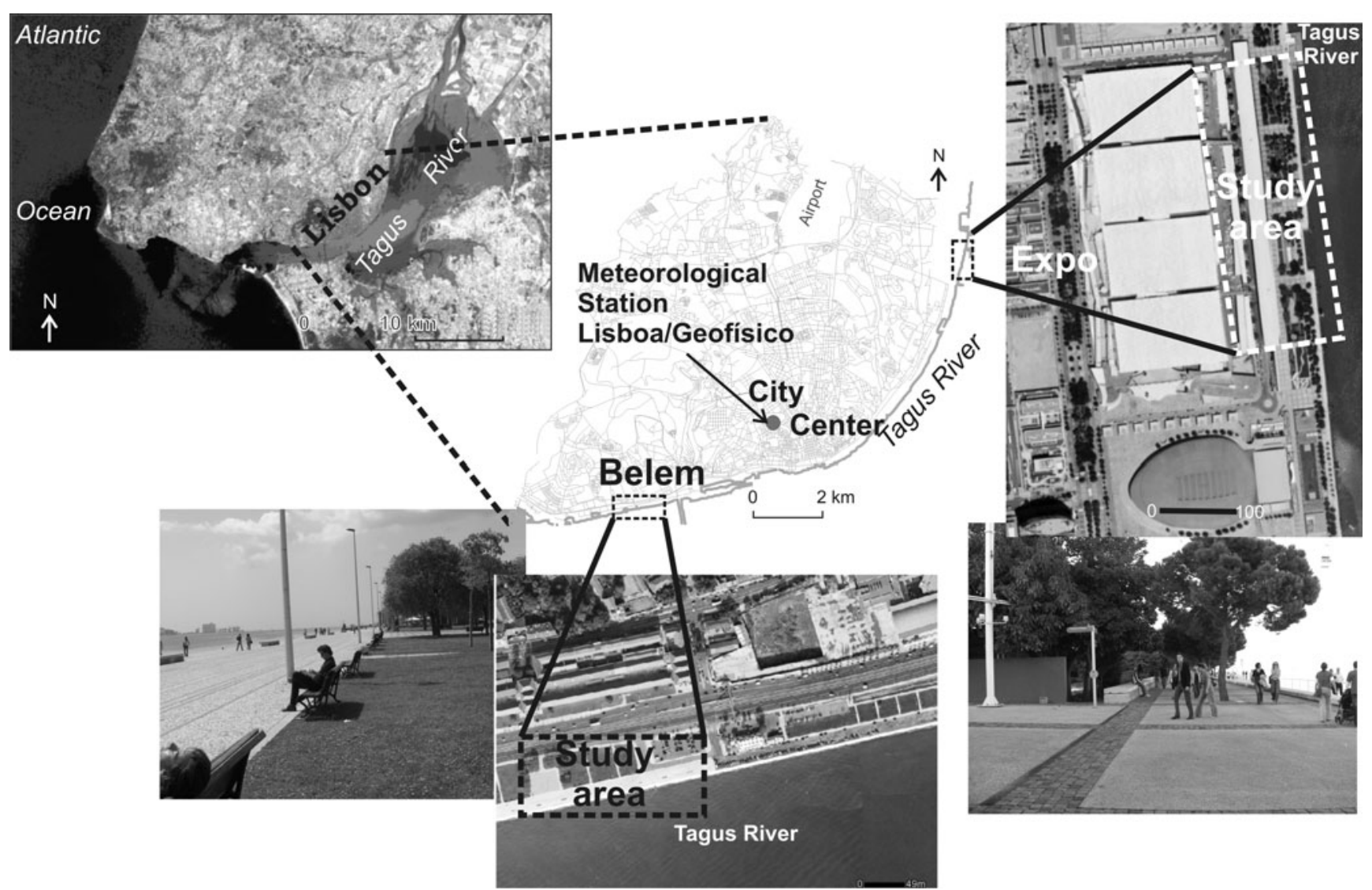

Fig. 1 Lisbon and the study areas

presented in this paper. According to De Dear and Brager 2002, there are two main aspects to consider in the thermal perception: sensation and satisfaction. Only the latter will be analysed in this paper, according to temperature or wind preferences expressed by the interviewed people (preference votes). The goals of this study are mainly exploratory and, unlike other research on the same topic (e.g. Hwang and Lin 2007; Lin and Matzarakis 2008), the significance of a given thermal physiological index (SET* and PET, respectively, in the mentioned works) was not assumed a priori; the research was instead directed towards seeking the variables or indices that related better with thermal or wind preferences votes, without any initial pre-conceived idea. Thus, the objectives pursued were: (1) to assess the relationship between bioclimatic comfort (expressed through preference votes) and the climatic and environmental conditions; and (2) to identify the personal parameters that influence the preference votes, namely temperature and wind in outdoor environments.

Multiple logistic regression was used to model the relationship between the preference votes and environmental and personal parameters. The results concerning the perception of temperature and wind speed are discussed separately, and the main conclusions outlined.

\section{Materials and methods}

This study was based on questionnaires, surveys and measurements of weather parameters performed simultaneously in Lisbon (Fig. 1), the capital and larger city of Portugal. Lisbon lies $30 \mathrm{~km}$ to the east of the Atlantic shore and right on the bank of the Tagus estuary, which is $15 \mathrm{~km}$ wide east of Lisbon (Fig. 1). The city has approximately 600,000 inhabitants and is the centre of a metropolitan area with nearly 2.5 million inhabitants. Lisbon has a "Mediterranean" climate, with mild winters and hot and dry summers.

\section{Study areas}

The field sessions were carried out in two open areas in Lisbon: Parque das Nações (the 1998 Expo site) that will be referred henceforth as 'Expo' and Alcântara, not far away from the Belem Tower, will be referred to shortly as Belem, Fig. 1). Both study areas are open outdoor spaces by the Tagus riverside, although each one has specific characteristics:

- Belem is located in the southern part of the city and is used for promenading and some sport activities (such as jogging, football and fishing), particularly during 
weekends. The area has paved sidewalks and grassed areas. There are benches facing south on both the green and paved areas. More than half the total area is covered by grass, but people use mainly the paved area, built with Portuguese limestone mosaic. The trees are around $10 \mathrm{~m}$ tall and are exclusively deciduous (Celtis australis) bordering the east and west sides and covering only about $20 \%$ of the area, which results in a low availability of shade. A total of 461 inquiries were made in Belem.

- Expo is also located by the Tagus, but north-east of the city centre. It offers a larger choice of leisure and commercial activities than Belem. The site where the fieldwork took place is almost entirely paved (about $70 \%$ of the area), built with a mixture of concrete and gravel; it has no grass, but it has many perennial trees (Pinus pinea, with an average height of $8-9 \mathrm{~m}$, and crowns that cover about $50 \%$ of the area; Fig. 1) supplying many shaded spots during the whole year. There are benches and low walls, with different orientations, providing many places to sit in the shade. A total of 482 interviews were carried out at the Expo site.

Field data collection

The field work included weather measurements, questionnaires and a photographic survey, carried out simultaneously. Measurements of air temperature (Ta), wind speed (v) and relative humidity (RH) were made every $30 \mathrm{~s}$, concurrently with the interviews (on average, 3 measurements were made during each interview). Solar $(\mathrm{K})$ and infrared radiation (L) were measured every $30 \mathrm{~min}$.

After the first experiment, described in Oliveira and Andrade (2007), a large number of additional measurements sessions and questionnaires were made in the study areas during 2006 and 2007, in order to account for different seasons and weather types.

\section{Calculation of mean radiant temperature and thermophysiological indices}

Mean radiant temperature $\left(\mathrm{T}_{\mathrm{mrt}}\right)$ is a parameter that measures the thermal influence of the radiant fluxes in the human body, and it was calculated using the method described in Jendritzky and Nübler (1981); it has been used in other works such as Spagnolo and De Dear 2003 and Oliveira and Andrade (2007). For each measurement session, radiant fluxes were measured and $\mathrm{T}_{\text {mrt }}$ was calculated in sunshine conditions (under direct solar radiation) and in the shade.

Thermophysiological indices were calculated in order to evaluate the combined effect of atmospheric variables on preference votes: Predicted Mean Vote (PMV; Fanger 1972; Jendritzky and Nübler 1981; Parsons 1993), Standard Effective Temperature (SET*; Parsons 1993; Chen et al. 2004) and Physiological Equivalent Temperature (PET; Höppe 1999; Matzarakis et al. 1999). Tabulated values of clothing insulation and metabolic heat production were used for the calculation of PMV and SET* (Parsons 1993), while constant values of clothing and physical activity were assumed for PET determination.

Several series of PMV, PET and SET* indices were calculated using different values of $\mathrm{T}_{\text {mrt }}$ : (1) referring to the location of the interviews (sun or shade); (2) only with $\mathrm{T}_{\text {mrt }}$ in the sun; and (3) only with $\mathrm{T}_{\mathrm{mrt}}$ in the shade and iv) considering $\mathrm{T}_{\mathrm{mrt}}=\mathrm{Ta}$.

Additional to the thermophysiological indices, an empirical coefficient $\left(v_{\chi}\right)$, combining two wind parameters was calculated, following the work of Oliveira and Andrade (2007); the authors found that the perception of wind depends strongly on a combination of maximum wind speed measured during each interview $\left(\mathrm{v}_{\max }\right)$ and the standard deviation of wind speed during the same period (SV); therefore, the $v_{\chi}$ coefficient was computed as follows: $V_{\chi}=v_{\max }+S V$. In this study, $V_{\chi}$ is used to evaluate the perception of atmospheric conditions instead of wind speed alone.

\section{Characterization of fieldwork days}

The fieldwork was carried out during the afternoons of 11 days of 2006 and of 2007, throughout the years.

Interviews were repeated in the summer 2007, in order to acquire a larger diversity of data for different weather types. Characterization of the fieldwork days is shown in Table 1. All days had clear weather conditions (absence of rainfall and cloudless or nearly cloudless sky), but there was a large variety of thermal and wind conditions; this allowed us to cover a representative sample of the different "promenade" weather conditions in Lisbon. Mean air temperature in the studied areas (calculated for each field work period that lasted for several hours during the hotter part of the day) varied between $14.6^{\circ} \mathrm{C}$ and $30.6^{\circ} \mathrm{C}$. Most of the fieldwork days had quite a high maximum air temperature. At the meteorological station Lisboa/Geofísico, located north of the city centre (Fig. 1), the majority of the days under study registered maximum temperatures that were higher than the maximum normal (30-year average), except in winter when they were slightly below the "normal", and in the 2007 summer period that was particularly cool. Wind speed was higher in the summer periods and, in spite of its lower average, the summer of 2007 had stronger wind than the summer of 2006 (90th percentile of wind speed $5.6 \mathrm{~m} \mathrm{~s}^{-1}$ on 22 July 2007; $4.6 \mathrm{~m} \mathrm{~s}^{-1}$ on 21 July 2006). 
Table 1 Characterization of the fieldwork days

\begin{tabular}{|c|c|c|c|c|c|c|}
\hline \multirow[t]{2}{*}{ Fiieldwork date } & \multirow{2}{*}{$\begin{array}{l}\text { Area } \\
\text { (see Fig. 1) }\end{array}$} & \multicolumn{4}{|c|}{ Average values in the study areas } & \multirow{2}{*}{$\begin{array}{l}\text { Maximum air } \\
\text { temperature }{ }^{b}= \\
\text { difference between } \\
\text { fieldwork day and } \\
\text { maximum monthly } \\
\text { mean }\end{array}$} \\
\hline & & $\begin{array}{l}\text { Air temperature } \\
\mathrm{Ta}\left({ }^{\circ} \mathrm{C}\right)\end{array}$ & $\begin{array}{l}\text { Relative humidity } \\
\text { RH (\%) }\left(\mathrm{m} \mathrm{s}^{-1}\right)\end{array}$ & Wind speed & $\begin{array}{l}\text { Global solar } \\
\text { radiation } \mathrm{K}\left(\mathrm{W} \mathrm{m}^{2}\right)\end{array}$ & \\
\hline $12-03-2006$ & Belem & 20.2 & 64.4 & 1.9 & 595.2 & +4.6 \\
\hline 23-04-2006 & Belem & 26.4 & 45.6 & 2.7 & 620.2 & +3.8 \\
\hline $13-05-2006$ & Expo & 26.9 & 43.0 & a & 627.0 & +2.9 \\
\hline 22-07-2006 & Expo & 28.4 & 48.1 & 1.3 & 872.5 & +0.4 \\
\hline 23-07-2006 & Belem & 30.6 & 43.6 & 3.0 & 811.2 & +2.2 \\
\hline $11-11-2006$ & Expo & 20.8 & 67.9 & 1.8 & 293.1 & +3.2 \\
\hline 12-11-2006 & Belem & 20.7 & 60.7 & 1.3 & 302.8 & +4.2 \\
\hline 03-02-2007 & Expo & 14.6 & 69.0 & 1.2 & 335.0 & -1.1 \\
\hline 04-02-2007 & Belem & 14.8 & 71.2 & 2.0 & 304.4 & -0.7 \\
\hline 21-07-2007 & Expo & 25.5 & 41.6 & 2.9 & 819.8 & -4 \\
\hline 22-07-2007 & Belem & 25.3 & 41.8 & 2.7 & 801.4 & -3.3 \\
\hline
\end{tabular}

${ }^{\text {a }}$ No data collection due to a technical failure

${ }^{\mathrm{b}}$ At the meteorological station of Lisboa/Geofísico (Fig. 1)

\section{The questionnaire}

The questionnaire was described in detail in Oliveira and Andrade (2007). It is divided into two parts: in the first one, the personal characteristics of the interviewees (age, gender, clothing, activity, geographical origin, among others) are described; in the second part, the questions aim at detecting the personal perception of the atmospheric conditions and the thermal and wind preferences of the interviewees. An important question in the first part of the questionnaire refers to the clothing worn by the interviewees. The procedure followed to classify clothing is explained in
Oliveira and Andrade (2007, p. 74); the estimation of the thermal resistance of clothing was based on Parsons (1993) and expressed in Clo units. In the second part, there are four questions about the perception of the atmospheric conditions (Oliveira and Andrade 2007, p. 76); in this work, only the questions referring to the preference votes associated with particular weather variables were analysed (questions 20 and 22, Table 2):

- The answers to question 20 showed which was the most unpleasant weather parameter for the interviewees at the time of the questionnaire;

Table 2 Questions 20 and 22 of the questionnaire

\begin{tabular}{|l|l|}
\hline $\begin{array}{l}\text { 20. What is the most unpleasant weather parameter at this } \\
\text { moment }\end{array}$ \\
\hline a. Temperature & \\
\hline b. Humidity & \\
\hline c. Solar radiation & \\
\hline$d$. Wind & \\
\hline$e$. None & \\
\hline
\end{tabular}

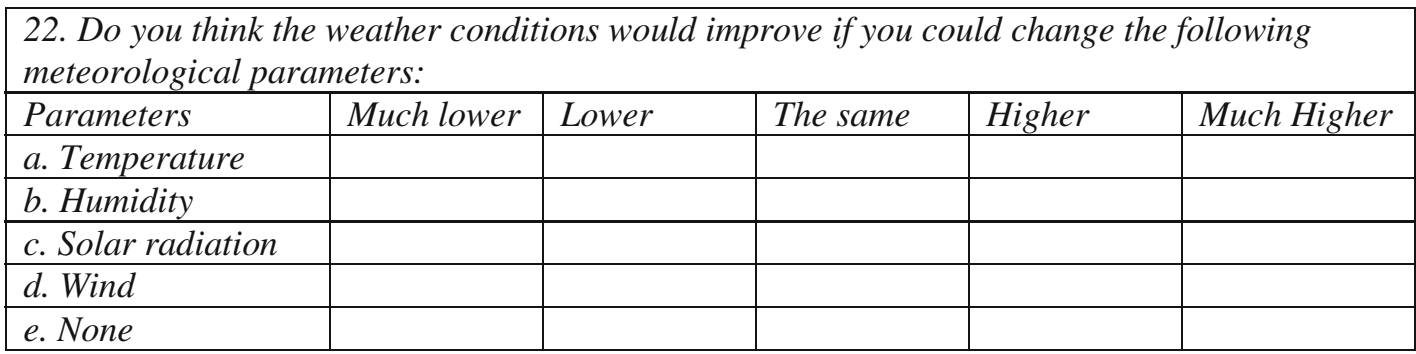


- The answers to question 22 indicated how the interviewees would like to modify any of the individual parameters in order to improve their satisfaction; this corresponds to Thermal Preference Votes or Wind Preference Votes. Although a seven-point scale could be more correct in theory (De Dear and Brager 2001; Spagnolo and De Dear 2003), a five-point scale was used in this study (following Stathopoulos et al. 2004), because it is likely to be more successful in street inquiries, where time and simplicity are crucial to obtain the interviewees' cooperation.

- Furthermore, the scale was reduced to 3 points during the analysis (merging points 1 and 2 as well as 4 and 5), as per the McIntyre scale (De Dear and Brager 2001; Hwang and Lin 2007; Memon et al 2008), since very few interviewees selected the extreme classes (much higher; much lower),

- The answers to this question show the subjective evaluation of the atmospheric conditions by the individuals (Parsons 1993) that relates to their state of comfort (defined as the level of mental satisfaction with the atmospheric conditions).

\section{Data analysis}

The main objective of the data analysis was to clarify the relationship between the personal characteristics of the interviewees, their thermal or wind preferences, and the measured values of the atmospheric parameters.

The analysis was centred on the preference votes (question 22), because the answers to this question have provided the most useful information concerning the environmental changes necessary to create more comfortable outdoor spaces.

Through this analysis, we tried to understand the conditions that can lead the interviewees to prefer maintaining or changing the atmospheric conditions perceived at that moment. In this sense, preference votes can be considered as a dependent categorical variable (Vitinghoff et al. 2005) and atmospheric and personal conditions as independent variables, which can also lead to a change in the answers.

Two main approaches were adopted:

1. Analysis of the relationship between specific independent variables (personal and atmospheric) and the preference votes. These relationships were tested using ANOVA (relationship between quantitative variables, such as air temperature or age) and Chi-square test (relationship between other categorical variables, such as gender or type of activity);

2. Modelling of the relationship between preference votes and the atmospheric and personal factors. For this purpose, logistic multiple regression was used (Kleinbaum et al. 1998; Vitinghoff et al. 2005). This method is useful to create models that predict the probability of occurrence of a binary variable (coded as 1 and 0 ) as a function of the independent variables (predictors), that can be either continuous or categorical (binary or not); categorization of atmospheric variables was made by dividing them in 10 categories of equal frequency (Vitinghoff et al. 2005). Other advantages of the logistic regression are that variables do not need to have a normal distribution or a constant variance and the relationships do not need to be linear. As the relationships can be nonlinear, different transformations (logarithmic, quadratic and others) were carried out and used in the initial model.

Each of the three categories of preference votes was considered, in the current analysis, as a different dependent variable according to the wish expressed by the interviewees to either maintain the present conditions (temperature, wind) or change them, hence increasing the value of the weather parameter or decreasing it. The preferred option was coded as 1 , while the other two types of answers were coded as 0 . For example, in relation to wind speed, all the votes of people who preferred to decrease wind speed were coded as 1 and all the other votes (not to decrease it) were coded as 0 . Therefore, for each of the atmospheric variables (temperature and wind), three models were necessary: preference to decrease, to maintain or to increase. In each model, the binary dependent variable was the coded vote and the independent variables were the atmospheric parameters measured at the moment, or the personal characteristics.

The independent variables to be included in the model were selected, in each case, through a forward stepwise procedure. The contribution of the independent variables to the model was evaluated using the Ward test and the change in $-2 \log$ Likelihood ( $-2 \mathrm{LL})$ when the variable is removed; the more significant contribution to the model corresponded to higher values of the Ward test and change in $-2 \mathrm{LL}$; variables with a significant contribution to the model have a $p$ value under 0.05 . The quantitative relationship between the probability of occurrence of the dependent variable and the different independent variables can be expressed as:

$p=\frac{1}{1+e^{-z}}$

where $p$ is the probability that the answer is given (varying between 0 and 1) and $z$ is the linear combination of the independent variables:

$z=b_{0}+b_{1} x_{1}+b_{2} x_{2}+\ldots+b_{n} x_{n}$

Where $b_{0}$ is the intercept of the model, the $x_{i}$ are the independent variables, and $b_{i}$ are the coefficients for each of 


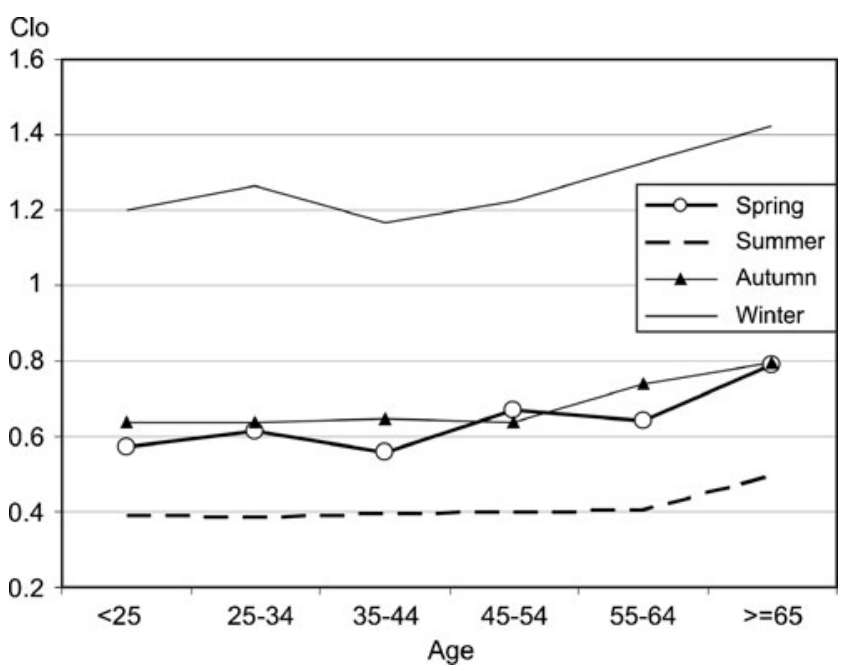

Fig. 2 Average Clo values by age group according to season

the $n$ independent variables (Kleinbaum et al. 1998; Vitinghoff et al. 2005).

It is not possible to calculate an overall measure of goodness of fit for this model, comparable to the $R^{2}$ in the linear multiple regression. However, the Hosmer-Lemeshow statistic can be used as an indicator of goodness of fit of the overall model; it is assumed that the model fits the data adequately when significance values associated with the chisquare are above 0.05 . This condition was fulfilled in the models applied in the current research.

\section{Results}

Characteristics of the interviewees

Women represented $53 \%$ of the sample and men $47 \%$; this gender distribution is very similar to the one observed in the national population. The most frequent age group was 25-34 years and the sample age structure was significantly younger than the national age structure (INE 2001). Nearly all the people interviewed were in the study areas for leisure purposes; $24 \%$ of the interviewed people were seated, $75 \%$ standing and, of these, a large majority were walking slowly $(90 \%)$ and only $5 \%$ were walking fast.

Estimated Clo values of the interviewees clothing varied between 0.24 and 1.75 (average 0.69), with the lower average values in summer (0.4) and the higher values in winter.

There are no significant differences in Clo values in relation to gender. However, qualitative differences exist, depending on season: women wearing skirts amounted to less than $1 \%$ in winter and autumn, but their number increased to around $10 \%$ in the summer. Conversely, age has a quantitative influence in clothing; there is an increment in the average Clo value in the age group above 54 years in winter and autumn, while in spring and summer, this increment is only clear in the age group above 65 years (Fig. 2).

Assessment of air temperature conditions

General aspects of the relationship between thermal preference votes and Ta by means of a polynomial regression

The relationship between thermal preference votes and measured values of Ta were significant $(p<<0.001)$. The relationship between the percentage of people who did not wish to change the thermal environment and the measured air temperature was analysed first. The sample was divided in 20 classes of equal frequency with increasing temperature (Fig. 3); this parameter explains nearly $84 \%$ of the variance of satisfaction, while a large variability was found in every temperature range. A total of $80 \%$ of people declared "want no change" with temperatures between 23 and $28^{\circ} \mathrm{C}$, but, even within this temperature range, some individuals voted for warmer $(15 \%)$ or cooler (5\%) conditions. Using the polynomial function of the regression, we computed that the maximum percentage of people that voted "no change" occurred at $24^{\circ} \mathrm{C}$, but the percentage values of pleased people for 23 and $25^{\circ} \mathrm{C}$ was very close to that of $24^{\circ} \mathrm{C}$ (only $0.1 \%$ difference).

The proportion of votes "want warmer" exceeded 50\% when temperature was below $17^{\circ} \mathrm{C}$, although there are individuals that declared they were pleased even with the lowest measured temperature values. The proportion of votes "want cooler" was very low for temperatures between 16 and $26^{\circ} \mathrm{C}$ ( $5 \%$ of interviewees) but this percentage increases rapidly above $26^{\circ} \mathrm{C}$, reaching over $50 \%$ when temperatures were above $32^{\circ} \mathrm{C}$.

The measured values of $\mathrm{Ta}$ and other atmospheric variables, as well as the seasonal context, must be considered in the interpretation of these results.

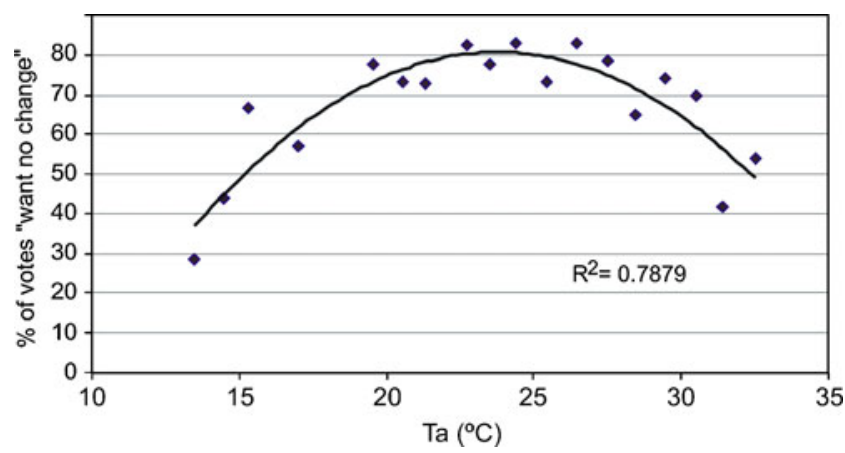

Fig. 3 Percentage of votes "want no change" versus Ta 
Fig. 4 Indoor versus outdoor Ta values when people voted "no change"

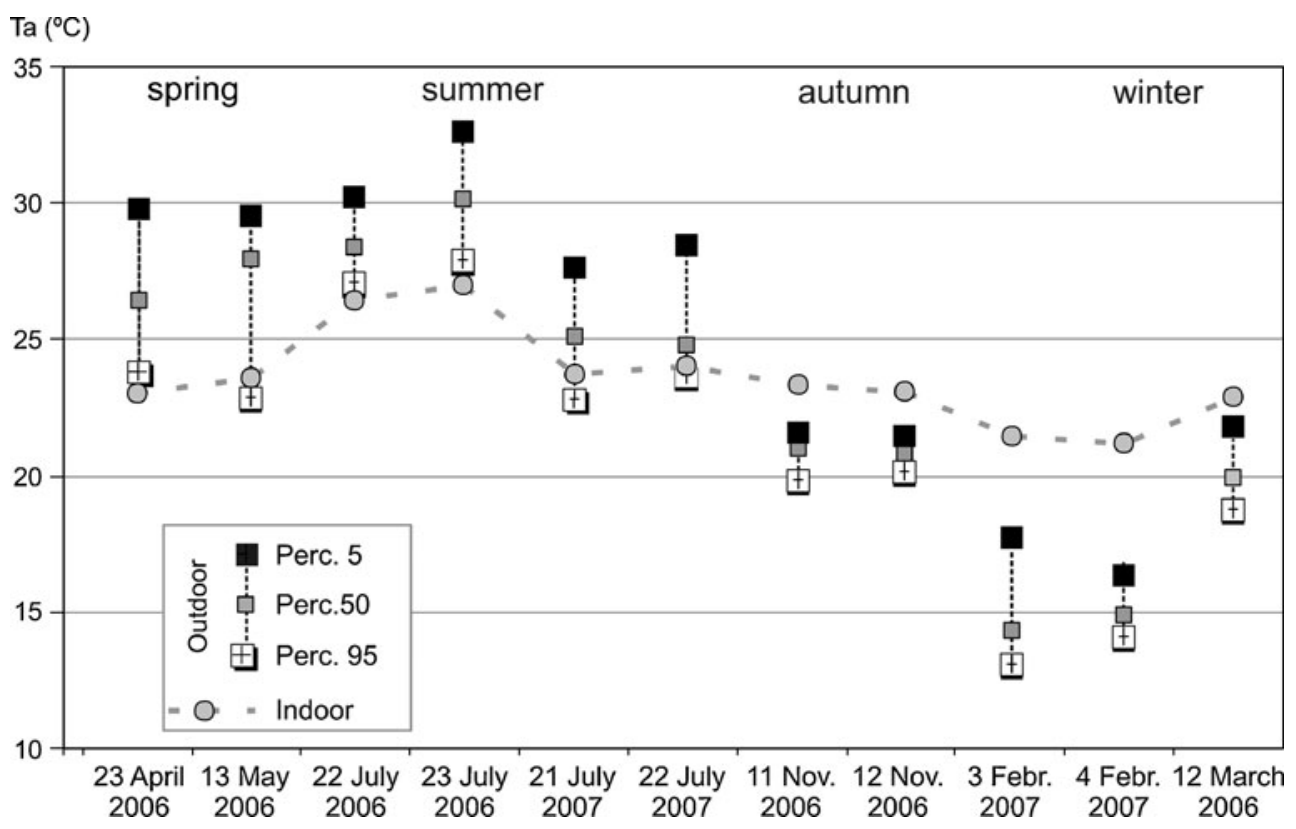

\section{The seasonal context}

Seasonal differences were analysed based on the calculation of the 5,50 and 95 percentiles of air temperature measured when people vote "want no change" in each day. As it can be expected, people vote "want no change" under much higher temperatures in summer than in the other seasons (Fig. 4).

However, there is a difference between the summer periods of 2006 and 2007: the latter was much cooler and windier (Table 1) and the comfort range in summer 2007 was $3-4^{\circ} \mathrm{C}$ below that of summer 2006, and was even lower than the comfort range in spring. In winter, the temperature range considered acceptable was between 13.1 and $17.8^{\circ} \mathrm{C}$. As could be expected, it was confirmed that a seasonal adaptation exists, which can be partially physiological although clothing may also play a major role (Fig. 4), allowing for lower temperatures to be tolerated in winter as well as higher ones in the summer. In addition, psychological factors can also play an important role such as the satisfaction with the first sunny and beautiful spring days (Höppe 2002).

\section{Relation with age}

The percentage of people that vote for changes in $\mathrm{Ta}$ decreases with age, as much under warm conditions as in cool conditions, but more clearly in a lower temperature context: $25 \%$ of people aged under 35 vote "want warmer" versus only $15 \%$ of those over 54 (Fig. 5). This can be partially explained by an average increase in clothing insulation in older people (Fig. 2). But a general decrease in sensitivity with age was also observed in hotter conditions: the lowest percentage of interviewees that voted changes was observed in the age group 55-64 years (6\%), while $12 \%$ of people under 35 preferred a lower temperature; however, in the oldest group, the percentage of these votes increases in comparison with the younger group, which can be related to the increase in clothing insulation in this age group in summer (Fig. 5).

\section{Modelling thermal preferences with multiple logistic regression}

The relationship between each of the 3 types of thermal preference votes (want cooler, want no change, want warmer) and a set of environmental and personal variables was tested. For each of the votes, the best fit model was selected and validated by the Hosmer-Lemeshow Test (Kleinbaum et al. 1998; Vitinghoff et al. 2005) (Table 3); a value above 0.05 indicates a good fit, to a significance level of 0.95. It can be seen in Table 3 that the three models allow a significant fit of the data. The contribution of each single variable to the model can be evaluated using the Wald statistics (higher values indicate a larger contribution

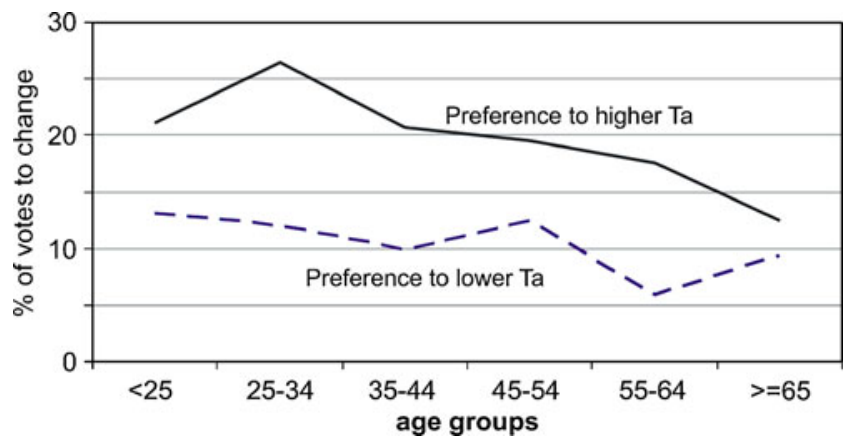

Fig. 5 Relationship between votes to change with Ta and age 
Table 3 Hosmer-Lemeshow Test in the model of prediction of thermal preference votes

\begin{tabular}{llll}
\hline Vote & Chi-square & $D f$ & Significance \\
\hline "Want warmer" & 13.227 & 8 & 0.103 \\
"Want cooler" & 2.069 & 8 & 0.979 \\
"Want no change" & 1.201 & 8 & 0.997 \\
\hline
\end{tabular}

to the model; $p$ must be $<0.05$ to be considered significant) and by the change in $-2 \log$ Likelihood (Tables 4 and 5).

\section{Thermal preference vote: "want warmer"}

Only three variables have a significant relationship with these votes: air temperature $(\mathrm{Ta})$, wind $(\mathrm{V} \chi$ see above) and age. The best agreement was obtained with Ta natural logarithm and with squared age (Table 4).

$\mathrm{Ta}$ is the most important variable that explains the change of the probability of the votes "want warmer", followed by age and $\mathrm{V} \chi$. The probability rises both with decreasing Ta and age and with increasing $\mathrm{V} \chi$.

The change in the probability to vote "want warmer" with changing Ta (Fig. 6) was simulated, for a 41-year old person (average age of the sample) using different values of $\mathrm{V} \chi$ : in the absence of wind and with Ta under $14^{\circ} \mathrm{C}$, the probability to vote "want warmer" exceeded 0.5 (more than a half of people preferring warmer); this threshold increases to 15.5 , 16 and $17^{\circ} \mathrm{C}$ with $\mathrm{V} \chi$ above 2,4 and $6 \mathrm{~ms}^{-1}$, respectively. The boundary above 0.75 of votes "want warmer" is only reached with Ta under $14^{\circ} \mathrm{C}$ and $\mathrm{V} \chi$ above $6 \mathrm{~ms}^{-1}$.

Influence of age combined with Ta can be seen in Fig. 7, for a constant $\mathrm{V} \chi$ of $3.4 \mathrm{~ms}^{-1}$ (average value of the sample). The threshold of the probability to vote "want warmer" $>0.5$ is reached with Ta under $17.5^{\circ} \mathrm{C}$ for an individual aged 20 , but only under $13.5^{\circ} \mathrm{C}$ to a 65 -year-old; for a 20 -year-old person, the boundary for the probability above 0.75 to vote "want warmer" is only reached at $13^{\circ} \mathrm{C}$, and it is never attained with the elderly people in the simulation.

\section{Thermal preference vote: "want cooler"}

The frequency of the votes "want cooler" was significantly related with $\mathrm{Ta}$, humidity and the natural logarithm of $\mathrm{V} \chi$
(Table 5). Ta and humidity were combined using the Humidex formula (ACSE 2004; Conti et al. 2005):

$H x=T a+\frac{5}{9}(e-10)$

in which $e$ is the vapour pressure in $\mathrm{hPa}$. The value of $e$ was calculated from measured Ta and RH. The best relationship was obtained with the square value of Hx. The estimated probability of voting cooler conditions rose with increasing $\mathrm{Ta}$ and humidity and decreased when $\mathrm{V} \chi$ increased.

The probability to vote "want cooler" was estimated for increasing Ta, with different $\mathrm{RH}$ values and without wind (Fig. 8). This estimation was made up to a Ta of $40^{\circ} \mathrm{C}$, well above the highest $\mathrm{Ta}$ measured $\left(33^{\circ} \mathrm{C}\right)$. This extrapolation was only carried out for situations without wind because, with very high $\mathrm{Ta}$, the thermal influence of wind changes, increasing sensible heat transfer from the atmosphere to the human body, therefore rising discomfort (Steadman 1979); Givoni (1998) indicates that with $\mathrm{Ta}$ above $37^{\circ} \mathrm{C}$ an increase in wind speed actually amplifies the sensation of heat. This effect was not included in the model and cannot be simulated from the measured data.

With $\mathrm{RH}=25 \%$, the probability of votes "want cooler" $>0.5$ was reached with $\mathrm{Ta}=35^{\circ} \mathrm{C}$, but if $\mathrm{RH}$ increases to 50 and $75 \%$, the same probability of people voting "want cooler" was reached at lower temperatures: respectively 29 and $25^{\circ} \mathrm{C}$.

An increase of wind induces a decrease on the probability to vote "want cooler" (within the boundaries of measured Ta values, as explained above). The probability to vote "want cooler" was calculated for an increasing value of $\mathrm{V} \chi$ (Fig. 9), with constant $\mathrm{Ta}$ and $\mathrm{HR}$ (respectively $30^{\circ} \mathrm{C}$ and $50 \%$ ). A slight increase in $\mathrm{V} \chi$ (from 0 to $0.8 \mathrm{~m} \mathrm{~s}^{-1}$ ) was enough to decrease the probability of "want cooler" vote below 0.7 ; conversely, when $\mathrm{V} \chi$ surpasses $4 \mathrm{~m} \mathrm{~s}^{-1}$, the decrease of the probability of the "want cooler" vote is very slight, never falling below 0.5 .

\section{Preference to maintain temperature: "want no change" vote}

Modelling the relationship between votes "want no change", concerning air temperature, and the independent variables is more complex than the previous ones, because
Table 4 Variables in the model of prediction of probability to vote "want warmer"

\begin{tabular}{lllllll}
\hline & B & SE & Wald & Sign. & $\begin{array}{l}\text { Change in }-2 \text { log } \\
\text { likelihood }\end{array}$ & Sign. \\
\hline $\ln \mathrm{Ta}$ & -4.74804 & 0.526974 & 81.18044 & $2.06 \mathrm{E}-19$ & 99.595 & 0.00000 \\
$\mathrm{~V} \chi$ & 0.0999 & 0.041962 & 5.667916 & 0.017278 & 5.067 & 0.02439 \\
Age $^{2}$ & -0.00031 & $9.41 \mathrm{E}-05$ & 10.66487 & 0.001092 & 12.109 & 0.00050 \\
Constant & 13.23889 & 1.557714 & 72.23171 & $1.91 \mathrm{E}-17$ & & \\
\hline
\end{tabular}


Table 5 Variables in the model of prediction to vote "want cooler"

\begin{tabular}{lllllll}
\hline & B & S.E. & Wald & Sign. & $\begin{array}{l}\text { Change in -2 Log } \\
\text { Likelihood }\end{array}$ & $\begin{array}{l}\text { Sign. of } \\
\text { the change }\end{array}$ \\
\hline $\mathrm{Hx} 2$ & 0.00331 & 0.00038 & 75.789 & $3.16 \mathrm{E}-18$ & 99.7938 & $1.69 \mathrm{E}-23$ \\
Ln V $\chi$ & -0.78607 & 0.339813 & 5.351076 & 0.020709 & 5.747166 & 0.016515 \\
Constant & -4.44587 & 0.577821 & 59.2008 & $1.42 \mathrm{E}-14$ & & \\
\hline
\end{tabular}

of the bipolar nature of discomfort (well expressed in Fig. 3) and the different interactions between Ta and the other variables on both sides of the Ta curve. The best relationship involving the probability of votes "want no change" was obtained with the PET values (classified in 10 classes of equal frequency), calculated with $\mathrm{Ta}=\mathrm{T}_{\mathrm{mrt}}$ $\left(\mathrm{PET}_{\text {shade }}\right)$. It can be considered that PET calculated in this way relates to conditions of shade, depending only on $\mathrm{Ta}$, wind speed and humidity. Although $\mathrm{T}_{\text {mrt }}$ measured in the shade may be higher than Ta in an urban context, due to multiple reflections and emissions, it should be noted that the present study was developed in open spaces, where these features are less important. However, as an average difference between $\mathrm{T}_{\text {mrt }}$ measured in the shade and Ta of $2^{\circ} \mathrm{C}$ was observed (Tmrt higher), the $\mathrm{PET}_{\text {shade }}$ indices were calculated for two values of $\mathrm{T}_{\mathrm{mrt}}$ (measured in the shade and $\mathrm{T}_{\mathrm{mrt}}=\mathrm{Ta}$ ), but the difference was not significant $(p>0.05)$. Therefore, the simplest procedure $\left(\mathrm{T}_{\text {mrt }}=\mathrm{Ta}\right)$ was used. The only other variable that contributes to the probability of votes "want no change" is a binary variable separating people over 54 years of age from the younger ones.

In the regression with a classified variable, the last class (in this case, the class $\mathrm{PET}_{\text {shade }}>27.7^{\circ} \mathrm{C}$ ) is taken as a reference class. The $\beta$ coefficients (Table 6) represent the variation of the probability of votes "want no change" in each class, relatively to the probability in the reference class, with the change in $\mathrm{PET}_{\text {shade. }}$

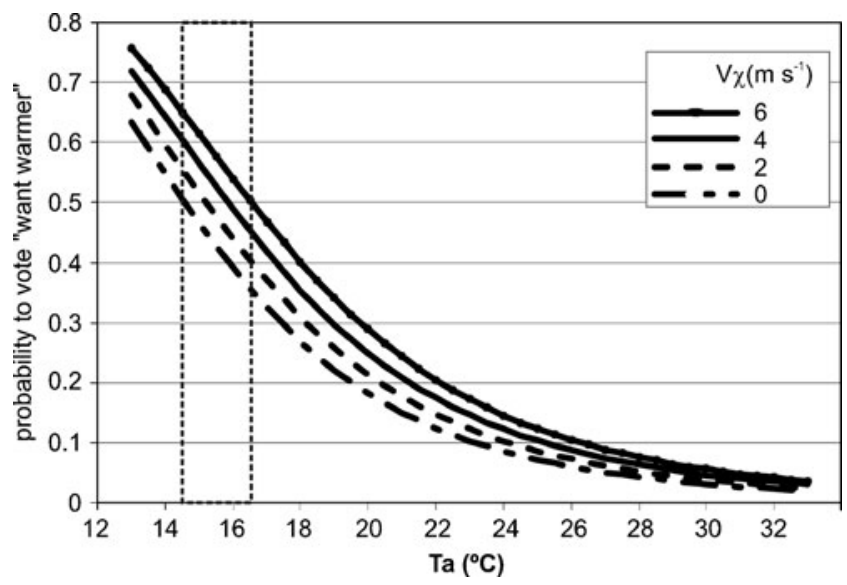

Fig. 6 Variation of probability to vote "want warmer" with Ta for different $\mathrm{V} \chi$ values (41-year-old individuals)
The probability of votes "want no change" is higher concerning people over 54 years of age, in accordance with the results presented above (Fig. 5); the average difference between the two age groups is 0.12 (Fig. 10).

Not all the $\mathrm{PET}_{\text {shade }}$ classes differentiate significantly from the reference group (only those where the Wald test has a significant value $(p<0.05)$ in bold in Table 6). Figure 10 identifies the classes in which the estimation of the probability of votes "want no changes" is significant $(p<$ 0.05 ). The lowest values of the probability of individuals wanting no change corresponded to the lower classes (Pet ${ }_{\text {shade }}$ under $14.7^{\circ} \mathrm{C}$; Table 6) and a clear decrease was

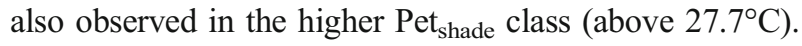

Maximum probability of votes "want no change" was observed in class $7\left(\mathrm{PET}_{\text {shade }}\right.$ between 21 and $\left.23^{\circ} \mathrm{C}\right)$. There was also a decrease (not significant) in the probability of votes "want no changes" within classes 4 to 6 (between 16.8 and $20.9^{\circ} \mathrm{C}$ ), although the $p$ value is always above 0.6 (therefore not significant). This variation is difficult to explain. These classes related mainly to inquires made during the autumn when there was a decrease in global solar radiation values (referring here to $\mathrm{K}$ measured under sunshine) in relation to class 3 (average global radiation value in class 3 was $383 \mathrm{~W} \mathrm{~m}^{2}$, decreasing to an average value of $283 \mathrm{~W} \mathrm{~m}^{2}$ in classes 4 and 5); in these classes, $82 \%$ of the votes "want change" corresponded to these conditions (autumn and low global radiation). However, the effect of solar radiation was not recognized as significant by the regression analysis.

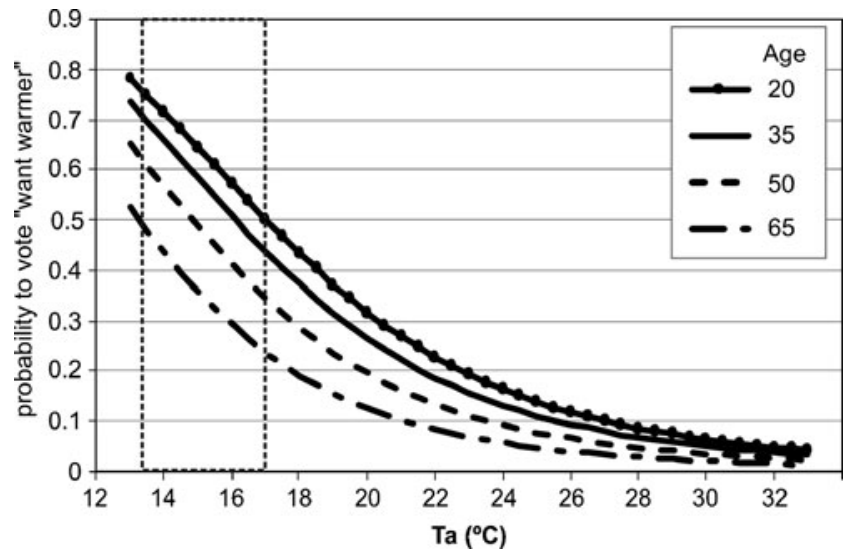

Fig. 7 Variation of probability to vote "want warmer" with Ta, for different ages at $\mathrm{V} \chi=3.4 \mathrm{~m} \mathrm{~s}^{-1}$ 


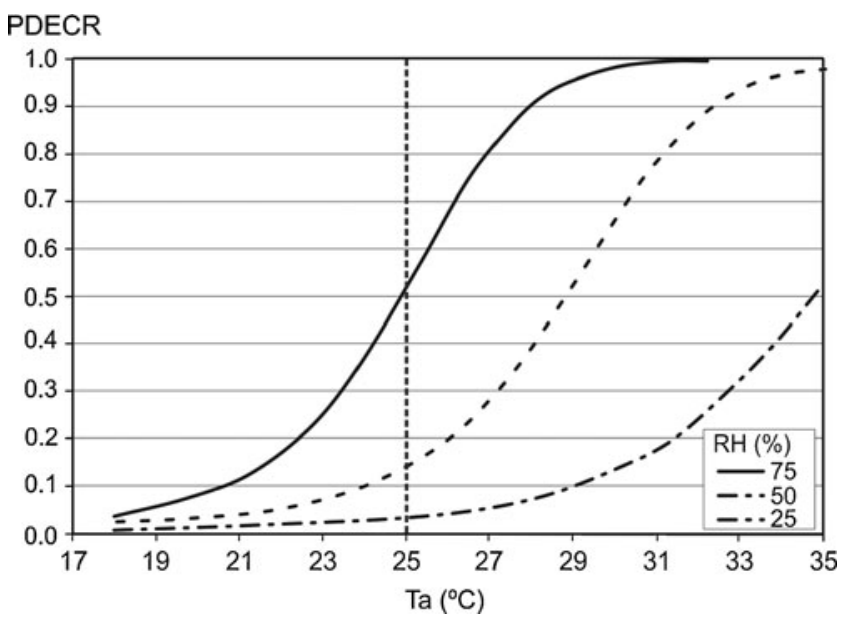

Fig. 8 Variation of probability to vote "want cooler" with Ta, without wind

\section{Assessment of wind}

General results

Wind has thermal and mechanical effects and both have implications on human comfort. Wind Preference Votes can be considered as a result of the combination of both effects.

Responses to question 22 showed that votes to decrease wind speed represented $30.6 \%$ of the sample; $67.1 \%$ voted for the maintenance of the values of wind speed and only $2.3 \%$ declared the preference for an increase in wind speed.

Votes to decrease wind speed were clearly more frequent in Belem than at the Expo site (respectively $37 \%$ and $25 \%$; the difference was significant; $p<0.001$ ). This difference is consistent with the difference between $\mathrm{v}$ at the two locations: average $\mathrm{v}$ was higher in Belem than at Expo ( $2.9 \mathrm{~m} \mathrm{~s}^{-1}$ and $2.2 \mathrm{~m} \mathrm{~s}^{-1}$, respectively), the difference also being significant $(p<0.001)$.

Wind was classified as the most unpleasant variable by $21 \%$ of people, mainly in spring ( $22 \%$ of interviewees) and during the summer 2007 (65\%); in opposition, in summer 2006, that was hotter than 2007 (Table 1), only 7\% of people classified $\mathrm{v}$ as the most unpleasant variable.

Oliveira and Andrade (2007) showed that the perception of wind depended not only on wind speed but also on turbulence and found a good correlation with $\mathrm{V} \chi$. Walton et al. (2007) also highlight the importance of wind gustiness on the outdoor thermal comfort.

Likewise, the current work, for which a much wider range of measured wind speeds ( 0 to $10.5 \mathrm{~m} \mathrm{~s}^{-1}$ ) under different thermal conditions was available, found that the $\mathrm{V} \chi$ coefficient was the strongest discrimination factor between different wind preference votes, when compared with average $\left(\mathrm{W}_{\mathrm{aver}}\right)$ or maximum values $\left(\mathrm{W}_{\max }\right)$ (Table 7).
Influence of gender and age

Oliveira and Andrade (2007) found a strong correlation between satisfaction with $\mathrm{V} \chi$ and gender. In the current work, the percentage of people that preferred not to change wind speed was calculated separately by gender, in 20 classes of equal frequency and increasing $\mathrm{V} \chi$. The difference between gender was confirmed (Fig. 11): $70 \%$ of men answered "want no change" against $61 \%$ of women. The difference was only evident for $\mathrm{V} \chi$ above $1.4 \mathrm{~m} \mathrm{~s}^{-1}$ and was particularly large above $3.1 \mathrm{~m} \mathrm{~s}^{-1}$ : $61 \%$ for men and $42 \%$ for women.

As with Ta, the general sensitivity to wind (more evident for higher values) decreased with age (Fig. 12). The percentage of votes to decrease was highest in the age group 25-34 years and minimum above 55; percentage of votes to increase was always very low and differences were not significant. As in relation to Ta, part of the decreasing dissatisfaction of people with wind when age increased can be due to heavier clothing usually worn by older people (Fig. 2), but it must be noticed that there was no significant association between clothing and satisfaction with wind.

\section{Modelling wind preferences with multiple logistic regression}

Logistic regression was used to model the relationship between wind preferences and the environmental and personal conditions. The low frequency of people that preferred to increase wind speed did not allow the creation of a significant model. Therefore, the probability to have votes to maintain is simply the complement of the probability of decrease type answers:

Probability of votes "maintain wind" $=1-$ (Probability of votes "decrease wind")

The overall model is significant, with a Chi-square value of 7.505 (significance of 0.4823 to 8 degrees of freedom).

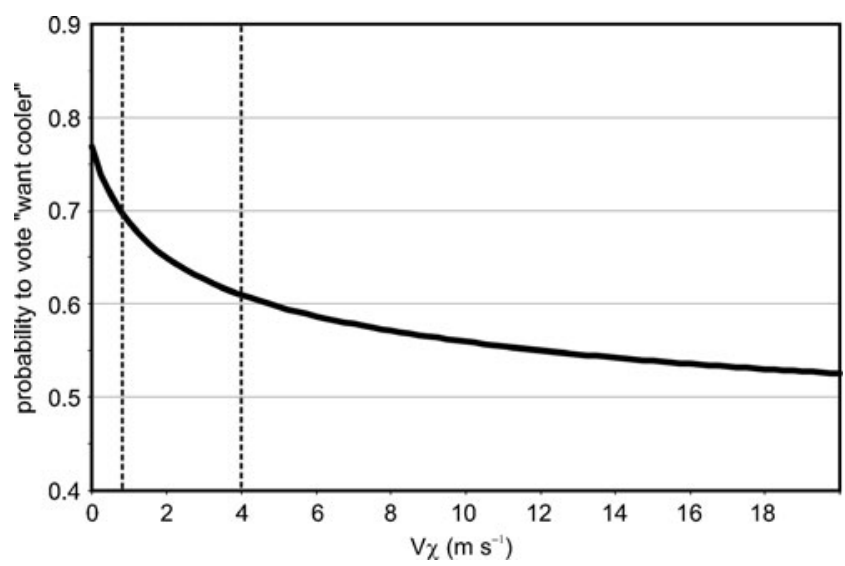

Fig. 9 Variation of probability to vote "want cooler" with $\mathrm{V} \chi\left(\mathrm{Ta}=30^{\circ} \mathrm{C}\right.$; $\mathrm{HR}=50 \%$ ) 
Table 6 Variables in the model of prediction of "want no change"

\begin{tabular}{|c|c|c|c|c|c|c|c|c|c|}
\hline \multirow[t]{2}{*}{ Age $>54(1)$} & \multicolumn{3}{|c|}{$\mathrm{PET}_{\text {shade }}$ in each class } & $\beta$ & Standard error & Wald & Sign. & \multirow{2}{*}{$\begin{array}{l}\text { Change in }-2 \log \\
\text { likelihood } \\
11.98661\end{array}$} & \multirow{2}{*}{$\begin{array}{l}\text { Sign. of } \\
\text { change }\end{array}$} \\
\hline & Min & Ave & Max & -0.83451 & 0.25127 & 11.0295 & 0.0008967 & & \\
\hline $\mathrm{PET}_{\text {shade }}$ class & & & & & & 54.76269 & $1.35158 E-08$ & & \\
\hline 1 & 8.4 & 9.4 & 10.2 & -1.03754 & 0.400226 & 6.720464 & 0.009531282 & 62.30004 & $4.82 \mathrm{E}-10$ \\
\hline 2 & 10.3 & 11.7 & 14.5 & -0.51116 & 0.385871 & 1.754796 & 0.185274902 & & \\
\hline 3 & 14.7 & 16.1 & 16.7 & 1.191605 & 0.454711 & 6.867412 & 0.008778167 & & \\
\hline 4 & 16.8 & 17.2 & 17.6 & 0.555644 & 0.387092 & 2.060464 & 0.151164099 & & \\
\hline 5 & 17.7 & 18.1 & 18.7 & 0.363948 & 0.375165 & 0.941094 & 0.331996757 & & \\
\hline 6 & 18.8 & 20 & 20.9 & 0.740865 & 0.39491 & 3.519506 & 0.060650525 & & \\
\hline 7 & 21 & 21.8 & 23 & 1.625034 & 0.484404 & 11.25407 & 0.000794484 & & \\
\hline 8 & 23.1 & 24.6 & 25.8 & 1.047984 & 0.419964 & 6.227101 & 0.012580954 & & \\
\hline 9 & 25.9 & 26.7 & 27.6 & 0.067105 & 0.375785 & 0.031888 & 0.858273176 & & \\
\hline 10 & 27.7 & 29.7 & 32.8 & & & & & & \\
\hline Constant & & & & 1.038472 & 0.347454 & 8.932954 & 0.002800711 & & \\
\hline
\end{tabular}

Significant values are in bold

Probability of votes to decrease is significantly related with $\mathrm{V} \chi$ (after logarithmic transformation), gender and age (Table 8). Probability is above 0.5 with $\mathrm{V} \chi>4 \mathrm{~m} \mathrm{~s}^{-1}$ for women, but this threshold was $7 \mathrm{~m} \mathrm{~s}^{-1}$ for men (Fig. 13 considering a constant age of 41 years). The value of probability of votes to decrease $=0.75$ was reached with $\mathrm{V} \chi=9.5 \mathrm{~m} \mathrm{~s}^{-1}$ for women and $14.5 \mathrm{~m} \mathrm{~s}^{-1}$ for men.

The thresholds of $\mathrm{V} \chi$ corresponding to 0.5 probability of votes "want to decrease" were not very different from those obtained with the polynomial function (PF) shown in Fig. 11 (identical for women, $0.5 \mathrm{~m} \mathrm{~s}^{-1}$ lower concerning men). But the performance of the two models is very different for higher $\mathrm{V} \chi$ (above $11.5 \mathrm{~m} \mathrm{~s}^{-1}$ ): with $\mathrm{PF}$, the probability of votes "want to decrease" never reached 0.75

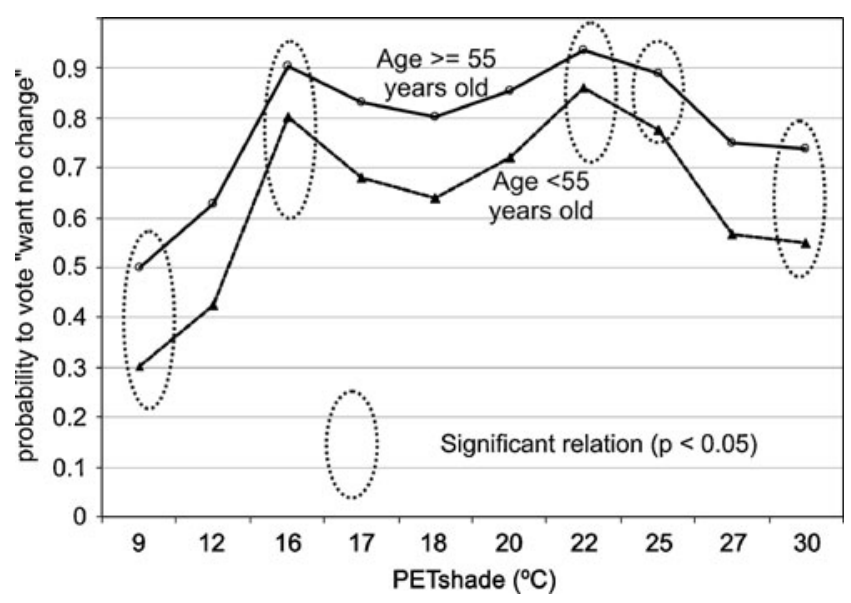

Fig. 10 Variation of probability to vote "want no changes" with $\mathrm{PET}_{\text {shade, }}$, for different age groups (maximum of 0.54 for men, 0.65 for women), while using logistic regression maximum values were 0.83 and 0.91 . The results of the logistic regression were clearly better adjusted to the observed values, in which answers "want to decrease" were $70 \%$ to men and $100 \%$ to women, for $\mathrm{V} \chi>11.5 \mathrm{~m} \mathrm{~s}^{-1}$.

Decreasing of probability of votes "want to decrease wind" with age is also obvious (Fig. 14): considering only women, the $\mathrm{V} \chi$ threshold to reach a value of probability $=0.5$ increases between $3.5 \mathrm{~m} \mathrm{~s}^{-1}$ and $6 \mathrm{~m} \mathrm{~s}^{-1}$, with age ranging from 20 to 65 years.

\section{Discussion}

It is widely acknowledged that human beings cannot feel thermal parameters, such as air temperature, individually (Parsons 1993; Höppe 1993). So, what are people actually talking about when they declared preference to change or maintain Ta?

Answers about the perception of Ta were strongly associated with wind. Atmospheric humidity also adds to

Table 7 Relation between wind (W) parameters and wind preference votes

\begin{tabular}{llll}
\hline & $F$ & $p$ & Critical $F$ \\
\hline $\mathrm{W}_{\text {aver }}$ & 26.6 & $<0.001$ & 2.615657 \\
$\mathrm{~W}_{\text {max }}$ & 30.9 & $<0.001$ & 2.615657 \\
$\mathrm{~V} \chi$ & 46.6 & $<0.001$ & 2.615657 \\
\hline
\end{tabular}




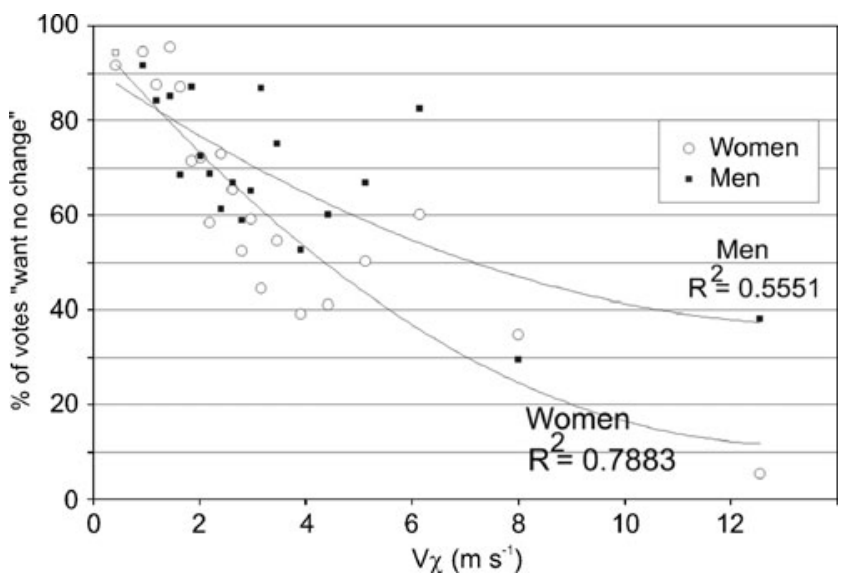

Fig. 11 Variation of the percentage of people that voted "no change" with increasing $\mathrm{V} \chi$ according to gender

the discomfort associated to high temperatures. It is therefore obvious that answers about Ta refer to a general thermal feeling, integrating the influence of different atmospheric parameters that the individuals could not isolate. The fact that people attach this feeling to Ta results from a widely spread pre-conceived idea that only $\mathrm{Ta}$ affects thermal comfort. The humidex formula ( $\mathrm{Hx})$ used as a predictor of the preference to decrease temperature (Fig. 8) lacks a theoretical basis, as opposed to the more sophisticated models (Fanger 1972; Gagge et al. 1986; Höppe 1993, 1997; Parsons 1993; Givoni 1998; Havenith 2001; Van Marken et al. 2007), but it has a long empirical confirmation, namely in Canada (ACSE 2004) and was related to mortality associated with heat waves in Italy (Bisanti et al. 2004; Conti et al. 2005). The present work showed that the statistical relation between Humidex and the thermal preference votes was clearly stronger than that of the indices based on energy balance of the human body, such as PET or SET*.

The importance of humidity in the model, even with moderate $\mathrm{RH}$ and $\mathrm{Ta}$, is somewhat surprising, because usually $\mathrm{RH}$ is only considered important when there is a combination of high values of both variables. The importance of humidity in thermal comfort can be strongly dependent on acclimatisation: for example, in Dacca, Ahmed (2003) only found a decrease in thermal comfort with RH well above $80 \%$ when $\mathrm{Ta}$ is around $30^{\circ} \mathrm{C}$ and wind speed $1.5 \mathrm{~m} \mathrm{~s}^{-1}$; according to the model developed for Lisbon, where hot and moist weather is very rare (Andrade and Alcoforado 2008), nearly $100 \%$ of people will declare discomfort with $30^{\circ} \mathrm{C}$ and $85 \% \mathrm{RH}$.

It is also known that radiant fluxes are very important to the human energy balance and therefore to thermal comfort (Hodder and Parsons 2006). Givoni et al. (2003) and Hwang and Lin (2007) used volunteers under outdoor controlled conditions to evaluate the influence of solar radiation on thermal comfort. This is a very different method from the one used in the present work, in which interviews were made, under non-controlled conditions, with people passing by in the study area and maintaining their usual behaviour. Thorsson et al. (2004), Stathopoulos et al. (2004) and Lin and Matzarakis (2008) also worked with "real users" of the studied areas, but they considered radiant temperature measured under direct solar radiation. In our case, values of $\mathrm{K}$ and $\mathrm{T}_{\text {mrt }}$ under these conditions showed a strong redundancy with $\mathrm{Ta}$ and they do not enhance the explanatory capacity of the models. Assuming that people spend as much time in the shade as in the sun, $\mathrm{K}$ and $\mathrm{L}$ were measured in the shade and $\mathrm{T}_{\mathrm{mrt}}$ was also calculated for shaded conditions; the inputs to the initial logistic regression model were $\mathrm{K}$ and $\mathrm{T}_{\mathrm{mrt}}$ under the same conditions (shade or sun) in which the individual was at the time of the interview. Even in this case, the contribution of $\mathrm{K}$ and $\mathrm{T}_{\mathrm{mrt}}$ to the models is not significant, because people easily change their radiant environment, by moving between direct $\mathrm{K}$ and shade, in response to the general thermal conditions. Times of permanency under these conditions are usually short and not sufficient to create a steady-state situation. In consequence, people exposed to direct $\mathrm{K}$ declared more frequently feeling cool than warm discomfort (they moved to the sun because they were cool) and people under the shade indicated the opposite sensation.

Clothing is one of the parameters included in the energy balance of the human body (Parsons 1993; Havenith et al. 2002), and it can be a cause of thermal discomfort. But changing clothing is one of the individual ways of thermal adaptation (Lin 2009). In a leisure situation, in which the choice is free, people easily change clothing as a function of the thermal conditions and nobody wears clothing that causes thermal discomfort; in the models developed in this study, clothing never gave a significant contribution to the explanation for thermal discomfort. The same cannot be said about situations in which people wear working clothes or uniforms, which can be highly inadequate to real thermal

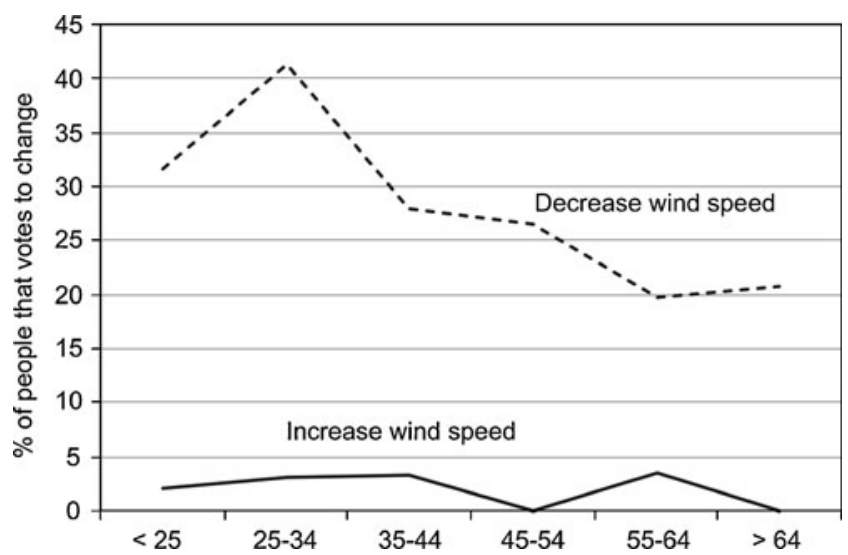

Fig. 12 Relationsip between votes "no change", wind and age 
Table 8 Parameters in the model of prediction of votes "want to decrease wind"

\begin{tabular}{lllllll}
\hline & B & S.E. & Wald & Sing. & \multicolumn{2}{c}{$\begin{array}{c}\text { Change in }-2 \text { log } \\
\text { likelihood }\end{array}$} \\
\hline Ln V $\chi$ & 1.663719 & 0.204267 & 66.33792 & $3.8 \mathrm{E}-16$ & 80.93549 & $2.33 \mathrm{E}-19$ \\
Age & -0.01602 & 0.006066 & 6.971931 & 0.00828 & 7.215517 & 0.007228 \\
Gender(1) & -0.675 & 0.197835 & 11.64117 & 0.000645 & 11.97951 & 0.000538 \\
Constant & -2.11253 & 0.390345 & 29.28929 & $6.23 \mathrm{E}-08$ & & \\
\hline
\end{tabular}

conditions, with negative consequences to comfort and even to health. Thorsson et al. (2004) concluded that $\mathrm{T}_{\mathrm{mrt}}$ explains $64 \%$ of Clo values for $\mathrm{T}_{\mathrm{mrt}}$ of $64 \%$, in an urban park of Gotebörg, Sweden. Nikolopoulou and Lykoudis (2006) also found a strong relationship between average air temperature and clothing, with regional differences at the European scale. The authors found that clothing is mainly a result of seasonal and daily general Ta and wind conditions (that can be represented by synoptic data) more than microscale conditions. Maybe in a more detailed analysis, small adjustments in clothing could be identified as a function of microscale conditions.

Another consequence of the adaptive behaviour is that thermophysiological indices, such as PET or SET*, calculated with the measured $\mathrm{T}_{\text {mrt }}$ on the human body, do not relate to the thermal perception declared by individuals (the bad fit between answers to interviews and the thermophysiological indices, even in indoor conditions, had already been pointed out in Auliciems and De Dear 1997). PET has a significant relationship with thermal votes "want no change" but only when calculated with $\mathrm{Ta}=\mathrm{T}_{\mathrm{mrt}}$, therefore depending only on Ta, wind and atmospheric humidity. This expresses the difficulty of using traditional steady-state models in the evaluation of outdoor thermal conditions, which are intrinsically transient. Another limitation of the use of thermal indices is that they take into account wind speed and not wind variability. It was found,

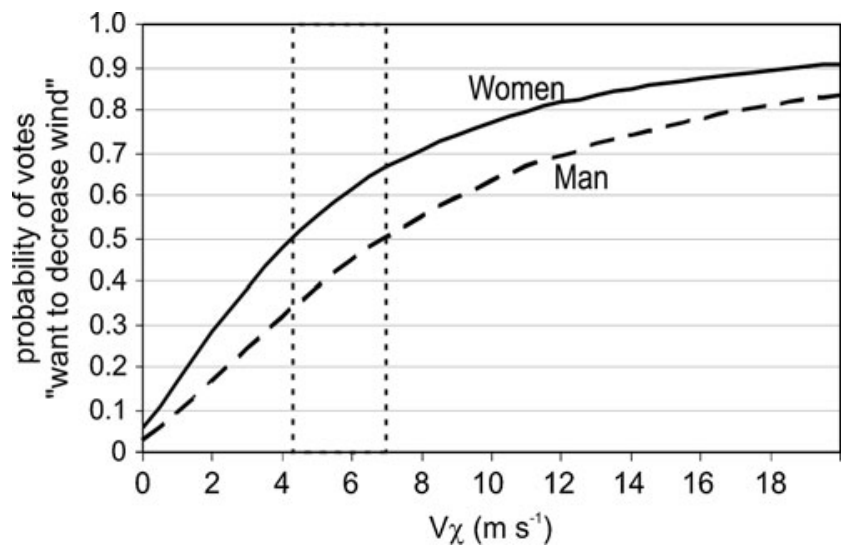

Fig. 13 Variation of probability of votes "want to decrease wind" with $\mathrm{V} \chi$ for both genders in the course of the current research, that the strongest influence of wind on the thermal perception results from the combination of speed and variability.

The maximum number of votes "want no change of temperature" was observed with $\mathrm{PET}_{\text {shade }}$ between 21 and $23^{\circ} \mathrm{C}$, which is within the "thermal comfort range" defined for PET in western Europe (Matzarakis et al. 1999). Strong decreases in the percentage of people that voted "no change" observed in Lisbon for temperatures below 14.7 and above $25.7^{\circ} \mathrm{C}$, were classified in Matzarakis et al. (1999) as slightly cool and slightly warm, respectively. These values are much lower than those found for Taiwan by Lin and Matzarakis (2008) (neutral range of PET between 26 and $30^{\circ} \mathrm{C}$ ) showing the importance of acclimation to thermal comfort. The importance of acclimation (to Ta values, not to PET, therefore not comparable with the values presented in this work) was also demonstrated by Nikolopoulou and Lykoudis (2006), who compared different European cities: annual neutral Ta ranged between $25.3^{\circ} \mathrm{C}$ in Thessaloniki and $13.3^{\circ} \mathrm{C}$ in Sheffield.

Other personal factors proved to be important in the answers, but not all the aspects referred by different authors (as time of permanence, motivation or expectation) presented an effective and quantifiable relation (De Dear and Brager 2002; Ahmed 2003; Nikolopoulou and Lykoudis 2006; Lin 2009). Motivation, for example, was probably too homogeneous (all interviewees were in the study areas

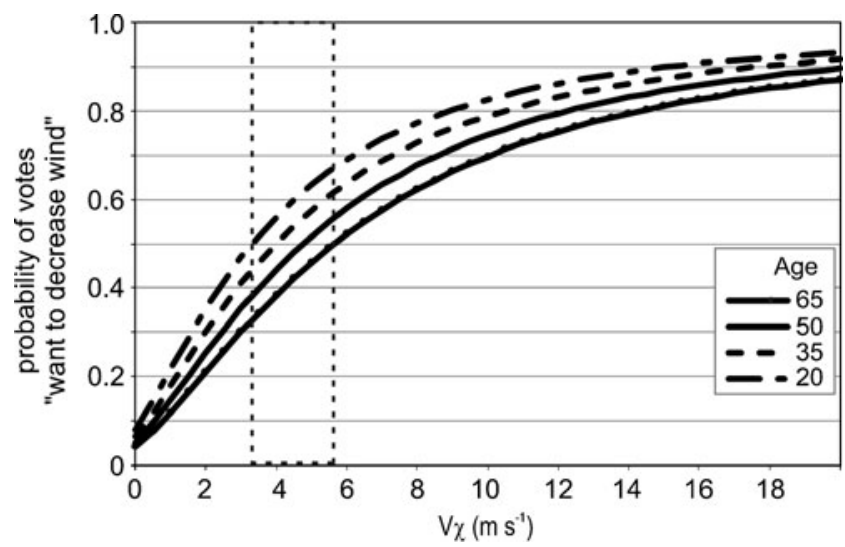

Fig. 14 Variation of probability of votes "want to decrease wind" with $\mathrm{V} \chi$ according to age in women 
for leisure purposes) and do not allow for a differentiation between answers; interviewees were asked about length of stay in the area, but it is difficult to reconstruct all the aspects of the stay, as for example the time spent in the sun or in the shade that can be important in understanding the answers. A more detailed analysis about this topic is needed, eventually using different methods.

The only personal factors with a significant relationship with declared preferences included in the logistic regression models were gender (with wind preference) and age (with wind and thermal preferences). This study confirmed the importance of gender in the perception of wind, which had already been observed by Oliveira and Andrade (2007). Several causes can be suggested to explain this difference between genders: physiological (lower average metabolic rate and body mass of women; ISO 1990; Parsons 1993) or cultural (men being more used to outdoor exposure or their larger reluctance to express discomfort), but it is a subject that cannot be fully explored in this work.

A very clear reduction of discomfort was observed with increasing age (either in relation to temperature or to wind). This decrease can be partly ascribed to higher clothing insulation in older people (Fig. 2), although elderly individuals also reported a lower discomfort under warm conditions. Therefore, in addition to differences in clothing, the general decrease of dissatisfaction with age can be related to a lower sensitivity to temperature variations of older people, as mentioned by some authors (Parsons 1993; Frank et al. 2000; DeGroot et al. 2006).

\section{Comparison with indoor comfort temperatures}

Testing the application of indoor models to outdoor conditions is an important and interesting topic. As Spagnolo and De Dear (2003) stated, it was frequently assumed that indoor thermal comfort standards can be generalised to outdoor conditions. However, this generalisation should be made carefully, because of the large differences not only between indoor and outdoor environments (outdoor is much more variable and difficult to control than indoor) but also between people's behaviour and psychological factors in the two distinct environments.

This study considered that the preferred range of outdoor Ta was bounded, for each day, by the 5th and 95th percentiles represented in Fig. 4; median can be considered the centre of this "comfort range".

The equation of De Dear and Brager (2002) was used to define an optimum comfort temperature for Lisbon:

$T_{\text {conf }}=0.31 T a_{\text {out }}+17.8$

In which $\mathrm{T}_{\text {conf }}$ is the optimum comfort temperature in naturally ventilated buildings and $\mathrm{Ta}_{\text {out }}$ is the outdoor mean temperature. This equation derives from a revision of the ASHRAE Standard 55, in an adaptive perspective (De Dear and Brager 2002), and is applicable to naturally ventilated buildings. In our case, $\mathrm{Ta}_{\text {out }}$ was the average daily $\mathrm{Ta}$ in the meteorological station Lisboa/Geofisico, for each day of fieldwork. The result is shown in Fig. 4.

In spring and summer, $\mathrm{Ta}_{\text {conf }}$ was always lower than the median outdoor preferred $\mathrm{Ta}$ and below the 5 th percentile on some days, as opposed to autumn and winter when $\mathrm{Ta}_{\text {conf }}$ is higher than the 95th percentile of the preferred outdoor Ta.

Besides the interference of other atmospheric variables and subjective parameters, the difference between indoor and outdoor preferred Ta can be partly explained by the seasonal change in clothing insulation (average Clo explains $83 \%$ of the variance of the difference between indoor $\mathrm{Ta}_{\text {conf }}$ and the median of preferred outdoor $\mathrm{Ta}$ ). In winter and autumn, heavy clothing allows people to tolerate much lower Ta values than the indoor standard, and in spring and summer lighter clothing leads to the opposite situation.

\section{Conclusion}

Interviews of "casual" users of outdoor facilities can give very different results from those obtained under controlled experimental conditions. The more complex and changeable conditions found in outdoor environments increase the difficulty of data analysis; however, this methodology led to more realistic results, mainly concerning the relationship with the variables that can be easily modified, such as solar exposure and clothing. Despite the complexity of the interactions between the declared comfort, the atmospheric conditions and the personal characteristics of the individuals, it was possible to identify patterns in these relations, using suitable methods; multiple logistic regression proved to be a useful tool to model the said relationships.

In accordance with the characteristics of the studied areas (leisure places), a high level of satisfaction with thermal and wind conditions was found: $88 \%$ of interviewees voted "no change" relative to these two parameters. The range of acceptability of outdoor conditions found in this type of places and activities is very wide and attainable through the adoption of adaptive strategies, like changes in clothing and moving between shade and full sunshine. However, it is also important to mention that $65 \%$ of people indicated different kinds of bioclimatic discomfort. This shows that an adequate planning of the open areas can significantly improve their microclimatic conditions and the general comfort of users.

It was also evident that the acceptability of warm conditions (high temperature, low wind speed) is much 
higher than the acceptability of cool conditions (low temperature-although moderate; strong wind speed). Between 23 and $28^{\circ} \mathrm{C}, 80 \%$ of people declared they were pleased, with a maximum of votes "want no change temperature" at $24^{\circ} \mathrm{C}$. Considering PET values (with $\mathrm{T}_{\text {mrt }}=$ $\mathrm{Ta}$ ), the comfort zone is very similar to that generally delimitated to western Europe $\left(18-23^{\circ} \mathrm{C}\right)$, although with a higher base $\left(21\right.$ instead $\left.18^{\circ} \mathrm{C}\right)$.

Very few people declared a preference for higher wind speed, even in hot weather, and, even then, there were people who declared a preference for lower wind speed and (less frequently) higher temperature. Answers about $\mathrm{Ta}$ were in agreement with the perception that overall thermal conditions are strongly influenced by wind, and by humidity in hot weather; humidity is important in the perception of warm conditions even with relatively low values of RH. Perception of wind was always better related to the combination of wind speed and variability rather than to wind speed alone. Age was the only personal factor significantly related with thermal preference (gender is strongly related to wind preferences), with a general decrease of discomfort with increasing age (mainly in the older classes-over 54 years).

This study shows that it is possible to define patterns of perception and preference of outdoor microclimatic conditions, even with a strong influence of personal (mainly gender and age) characteristics. We believe that the current work gives a basis for understanding the perception of outdoor microclimatic conditions in leisure areas, in a city with a moderate thermal climate like Lisbon. The continuation of this research will be directed towards more concrete topics, related for example to the impact of certain landscape features in the bioclimatic comfort. A subsequent step is the application of this information to help design more comfortable outdoor leisure areas. To achieve this aim, a strong interdisciplinary dialogue is needed between the different experts involved in that task.

Acknowledgements This study was developed in the framework of the project "URBKLIM: Climate and urban sustainability. Perception of comfort and climatic risks" (POCI/GEO/61148/2004), co-financed by FCT and FEDER (Operational Programme for Science and Innovation 2010).

\section{References}

ACSE (American Society of Civil Engineers) (2004) Outdoor human comfort and its assessment. ACSE, Reston

Ahmed KS (2003) Comfort in urban spaces: Defining the boundaries of outdoor thermal comfort for the tropical urban environments. Energy Build 35:103-110

Andrade H, Alcoforado MJ (2008) Microclimatic variation of thermal comfort in a city-district of Lisbon (Telheiras). Night-time period. Theor Appl Climatol 92:225-237
Auliciems A, De Dear R (1997) Thermal adaptation and variable indoor climate control. In: Auliciems A (ed) Advances in bioclimatology - 5 . Human bioclimatology. Springer, Queensland, Australia, pp 61-86

Bisanti L, Cadum E, Costa G, Michelozzi P, Perucci C, Russo A (2004) Heat waves and mortality in Italy. Epidemiology 15:97

Chen F, Kusaka H, Tewari M, Bao J-W, Hirakuchi H (2004) Utilizing the coupledWRF/LSM/Urban Modeling System withdetailed urban classification to simulate theurban heat island phenomena over theGreater Houston Area. 5th Conference onUrban Environment, Vancouver, BC,Canada, 23-27 August 2004

Conti S, Meli P, Minelli G, Solimini R, Toccaceli V, Vichi M, Beltrano C, Perini L (2005) Epidemiologic study of mortality during the summer 2003 heat wave in Italy. Environ Res 98:390-399

de Dear R, Brager GS (2001) The adaptive model of thermal comfort and energy conservation in the built environment. Int $\mathrm{J}$ Biometeorol 45:100-108

de Dear R, Brager GS (2002) Thermal comfort in naturally ventilated buildings: revisions to ASHRAE Standard 55. Energy Build 34:549-561

INE (Instituto Nacional de Estatística) (2001) Recenseamentos Gerais da População e da Habitação. Dados comparativos 1991-2001. Lisboa, INE (CD-ROM

DeGroot DW, Havenith G, Kenney WL (2006) Responses to mild cold stress are predicted by different individual characteristics in young and older subjects. J Appl Physiol 101:1607-1615

Fanger PO (1972) Thermal comfort. McGraw-Hill, New York

Frank SM, Raja SN, Bulcao C, Goldstein (2000) DS. Age-related thermoregulatory differences during core cooling in humans. Am J Physiol Regul Integr Comp Physiol 279:R349-R354

Gagge AP, Fobelets AP, Berglund LG (1986) A standard predictive index of human response to the thermal environment. ASHRAE Trans 92:709-731

Givoni B (1998) Climate considerations in building and urban design. Wileyc, New York

Givoni B, Noguchi M, Saaroni H, Pochter O, Yaacov Y, Feller N, Becker S (2003) Outdoor comfort research issues. Energy Build 35:77-86

Havenith G (2001) An individual model of human thermoregulation for the simulation of heat stress response. J Appl Physiol 90:1943-1954

Havenith G, Holmer I, Parsons K (2002) Personal factors in thermal comfort assessment: clothing properties and metabolic heat production. Energy Build 34:581-591

Hodder S, Parsons KC (2006) The effects of solar radiation on thermal comfort. Int J Biometeorol 51:233-250

Höppe P (1993) Heat balance modelling. Experientia 49:741-747

Höppe P (1997) Aspects of human biometeorology in past, present and future. Int J Biometeorol 40:19-23

Höppe P (1999) The physiological equivalent temperature - an universal index for the biometeorological assessment of the thermal environment. Int J Biometeorol 43:71-75

Höppe P (2002) Different aspects of assessing indoor and outdoor thermal comfort. Energy Build 34:661-665

Hwang RL, Lin TP (2007) Thermal comfort requirements for occupants of semi-outdoor and outdoor environments in hothumid regions. Archit Sci Rev 50:60-67

ISO (International Standards Organisation) (1990) Ergonomics of the thermal environment: estimation of metabolic heat production. International Standards Organisation, Geneva

Jendritzky G, Nübler W (1981) A model analysing the urban thermal environment in physiologically significant terms. Arch Met Geoph Biokl B 29:313-326

Kleinbaum DG, KupperAssistant LL, Nizam A, Muller KA (1998) Applied regression analysis and multivariable methods. Duxbury, Pacific Grove

Knes I, Thorsson S (2006) Influences of culture and environmental attitude on thermal, emotional and perceptual evaluations of a public square. Int J Biometeorol 50:258-268 
Lin TP (2009) Thermal perception, adaptation and attendance in a public square in hot and humid regions. Build Environ 44:20172026

Lin TP, Matzarakis A (2008) Tourism climate and thermal comfort in Sun Moon Lake, Taiwan. Int J Biometeorol 52:281290

Matzarakis A, Mayer H, Iziomom E (1999) Applications of a universal thermal index: physiological equivalent temperature. Int J Biometeorol 43:76-84

Memon RA, Chirarattananon S, Vangtook P (2008) Thermal comfort assessment and application of radiant cooling: a case study. Build Environ 43:1185-1196

Nikolopoulou M, Lykoudis S (2006) Thermal comfort in outdoor urban spaces: analysis across different European countries. Build Environ 41:1455-1470

Oliveira S, Andrade H (2007) An initial assessment of the bioclimatic comfort in an outdoor public space in Lisbon. Int J Biometeorol $52: 69-84$

Parsons KC (1993) Human thermal environments. Taylor \& Francis, London
Spagnolo J, de Dear R (2003) A human thermal climatology of subtropical Sydney. Int J Climatol 23:1383-1395

Stathopoulos T, Wu H, Zacharias J (2004) Outdoor human comfort in an urban climate. Build Environ 39:297-305

Steadman RG (1979) The assessment of sultriness. Part I: a temperature humidity index based on human physiology and clothing science. J Appl Meteorol 18:861-873

Thorsson S, Lindqvist M, Lindqvist S (2004) Thermal bioclimatic conditions and patterns of behaviour in an urban park in Göteborg, Sweden. Int J Biometeorol 48:149-156

Van Marken Lichtenbelt WD, Frijns AJ, van Ooijen MJ, Fiala D, Kester AM, van Steenhoven AA (2007) Validation of an individualised model of human thermoregulation for predicting responses to cold air. Int J Biometeorol 51:169-179

Vitinghoff E, Glidden DV, Shiboski SC, McCulloch CE (2005) Regression methods in biostatistics, linear, logistic and repeated measures models. Springer, New York

Walton D, Dravitzki V, Donn M (2007) The relative influence of wind, sunlight and temperature on user comfort in urban outdoor spaces. Build Environ 42:3166-3175 